\title{
Determinants of Male Involvement in Family Planning Services: A Case Study in the Tema Metropolis, Ghana
}

\author{
Stephen Manortey*, Kenneth Missah \\ Ensign College of Public Health, Kpong, Eastern Region, Ghana \\ Email: *steve.manortey@ensign.edu.gh
}

How to cite this paper: Manortey, S. and Missah, K. (2020) Determinants of Male Involvement in Family Planning Services: A Case Study in the Tema Metropolis, Ghana. Open Access Library Journal, 7: e6043.

https://doi.org/10.4236/oalib.1106043

Received: December 31, 2019

Accepted: January 16, 2020

Published: January 19, 2020

Copyright $\odot 2020$ by author(s) and Open Access Library Inc.

This work is licensed under the Creative Commons Attribution International License (CC BY 4.0).

http://creativecommons.org/licenses/by/4.0/

\begin{abstract}
Background: Usage of family planning services in developing countries has been found to avert unintended pregnancies, and drastically reduce maternal and child mortality. Men as the main decision-makers in most of African families have an important role to play towards acceptance of family planning methods; however, its usage still remains low. The primary objective of this study was to investigate the factors that influence male involvement in family planning. Method: This was a descriptive cross-sectional study conducted within the Tema Metropolis in the Greater Accra Region of Ghana. The chosen research approach provided an opportunity to interact with adult male respondents to access their perceived factors that contribute to their level of involvement in family planning programs. A stratified sampling technique was used to recruit 227 participants aged (19 - 58) years using a well-structured questionnaire. Univariate, bivariate and multivariate analyses were respectively conducted to estimate frequencies, measure the level of associations and predict outcomes on selected variables outputs. Results: The study revealed that a little over two-thirds (68.72\%) of the respondents disagreed that total family planning is an issue for only women. The majority $(83.26 \%)$ of the respondents, said their communities accept the act of men accompanying their wives or partners for family planning services, though $36.12 \%$ of them reported that their family and friends see it strange for men to attend family planning with their wives/partners. Among the $34.4 \%$ of respondents who reported ever attending any such family planning clinic, $56.41 \%$ have attended just once. Marital status, employment status and knowledge about family planning of respondents were positively associated with male involvement in family planning ( $\mathrm{p}$-value $<0.05$ ). The odds of a male involvement in family planning progressively increase in relationship to the depth of knowledge one has on family planning. However, being old (46 - 58 yrs), unmar-
\end{abstract}


ried and self employed, significantly served as protective factors against male participation in family planning. Conclusion: In this study, the level of male involvement was low, although most men were aware of family planning in the Tema Municipal. Old age, being unmarried and self-employed were the factors that influence male involvement in family planning. Thus, there is a need for the office of the Metro Health Directorate to intensify health education on the benefits of family planning with male involvement. The family planning programs should incorporate the responsibility and role of males in the uptake of family planning service.

\section{Subject Areas}

Public Health

\section{Keywords}

Family Planning, Male Involvement, Tema, Ghana

\section{Introduction}

Family planning is a deliberate effort of couples to regulate the number of children and spacing at birth. It aims at improving family lives at the micro-level and contributes to the sustainable effort at the macro level. Family planning is a way of controlling the population and helps in reducing unintended pregnancies [1]. Direct and indirect benefits of family planning include the reduction in the spread of HIV to newborn babies [2]; reduction of maternal mortality and morbidity [3]; reduction in neonatal, infant and child mortality [4]; reduction recourse to often unsafe abortion [5] and improvement in education and employment opportunities for women who are able to delay initiation of childbearing [6]. The World Health Organization (WHO) explained that despite great progress over the years, many women worldwide want to prevent pregnancy but they and their partners are not using contraceptives and some of the reasons for this unmet need are quality of service, unavailability of range of methods, fear of opposition from partners and worries of side effects and health concerns among others [7]. One factor that deserves attention is the involvement of males in family planning.

Male involvement in family planning means more than increasing the number of men using condoms and having vasectomies; it also includes the number of men who encourage and support their partners in contraception and encourage peers to use family planning and who influence the policy environment to be more conducive to developing male-related programmes. In this context, male involvement should be understood in a much broader sense than male contraception and should refer to all organizational activities aimed at men as a discrete group, which has the effect of increasing the acceptability and prevalence of family planning practice of either sex [8].

Until recently, fertility and family planning research in developing countries, 
as well as policy and program formulation, have generally relied on data collected from women. Increasingly, however, attention is being paid to the inclusion of men. The reasons for the new interest in men are not hard to find. First, information that has become available from surveys conducted over the past decade suggests that men and women do not necessarily have similar fertility attitudes and goals [9]. Second, the scope of fertility and family planning research has expanded to include such broader reproductive health issues as sexually transmitted diseases, on which data from both men and women are needed [2]. Although women bear children and most modern contraceptives are female-centered, childbearing has an impact on the lives of men too. This impact may be felt financially if men accept the responsibility of supporting their children and in a range of other ways, including the health and well-being of their wives and children. Often, a man's social status is also affected when he becomes a father [10].

The male partner may play an impact role in decision-making regarding contraceptive use and the number of children they would like to have. In some countries or among some social groups, according to Lasee and Becker (1997), the male partner has greater influence than his spouse [11]. A study by Ezeh (1993) in Ghana revealed that, a wife's attitude toward contraception is strongly influenced by her husband's attitude and background characteristics, especially education but the husband's views are similarly influenced by his wife [12].

Family planning in Ghana dates as far back as 1956 [13]. However, studies have shown that uptake of family planning in Ghana has not been encouraging. The 2011 Multiple Indicator Cluster Surveys (MICS), reported that the contraceptives prevalence rate among women in Ghana was $34.7 \%$ and about $26.4 \%$ of women had an unmet need for family planning [14]. The facts indicate low use of contraceptives use among Ghanaian women. The prevalence of contraceptive use is lowest among currently married women in the youngest and oldest age groups. Married women in urban areas are more likely to use contraceptives methods than married women in rural areas. The contraceptive prevalence rate (CPR) among women was highest in the Volta Region and lowest in the Northern Region [15].

On the other, the perception that men will necessarily have more influence on reproductive decisions because they typically control the family's assets, and are accepted as the household head and are older, may be an exaggeration. The actual situation is likely to depend on other factors that vary over time and by location. For instance, among the Yoruba of Nigeria, the fertility desires of both marriage partners are important predictors of the couple's fertility. However, whereas the husband's desire is dominant in predicting the couple's behavior when the number of living children is small, the wife's desire becomes more important as the number of children grows [10]. In Taiwan, a study by Dewi (2009), observed that when spouses disagree over whether to have another child, the wife tends to prevail [16].

The cause of the low involvement of males in family planning is believed to be 
as a result of several factors. These factors include male's perception of family planning, their socioeconomic and demographic profiles, national policies in place, mass media campaigns, inter-personal communication from health workers, advice from family members, spousal communication and health systems in place [17]. According to Ijadunola et al. (2010), there is an urgent need to increase male involvement in family planning in Ghana. Low levels of knowledge, social stigma, shyness, embarrassment, and job responsibilities contribute to the low involvement of males in family planning [18].

According to the 2014 Ghana Demographic and Health Survey (GDHS), only $27 \%$ of married women use family planning with $22 \%$ using a modern method and 5\% using traditional methods and 30\% have an unmet need for family planning [15]. There is high unmet need for family planning hence the need to involve the male partner. Adongo et al. (2006), tried to examine men's concerns about reproductive health services in a rural Sahelian setting of Northern Ghana whiles focusing on the Zurugelu community and found out that community mobilization and male outreach was not sufficient for introducing behavioural change. Uptake of contraceptive services was greater and more sustained among the Zurugelu when combined with Community-Based Health Planning and Services (CHPS) and Community Health Officers (CHO) services than when Zurugelu lacked supporting $\mathrm{CHO}$. Introducing $\mathrm{CHPS}$ and the services of $\mathrm{CHO}$, to focus on men in the Zurugelu community, sustained and significantly improved reproductive change in the area [19].

Studies have shown that there are certain hindrances to males' utilization of family planning services though males play an important role in reproductive health. According to a demographic health survey done in Ilorin, Nigeria, family planning clinics are oriented to women, therefore, men often feel uncomfortable and unwelcome in these clinics [20]. Failure to involve men in family planning programs can have serious implications. Even when women are educated and motivated to practice contraception, they may not do so because of opposition from their husbands. Individuals interviewed in urban Sudan believed that the male partner decides if a couple will use contraceptives and if they do choose the method [21].

The study, therefore, aimed at determining the proportion of males involve in family planning and also explore the determinants that influence their involvement in the practise within the Tema Metropolis in the Greater Accra Region of Ghana.

\section{Methods}

\subsection{Profile of the Study Area}

Tema Metropolis is one of the 26 districts of the Greater Accra Region, located in the southeastern part of Ghana. The Tema Metropolis is a virtually fully-built up area. It is a vibrant commercial and industrial city-about the only well-planned city in the country. It has a large harbor; one of the world's biggest 
man-made harbors which is the main seaport entry to Ghana. The Tema Metropolis is bounded in the North-East by Ashaiman Municipality, in the North-West by Adentan Municipality, on the West by Ledzokuku-Krowor Municipality, in the South by the Gulf of Guinea and in the East by the Kpone-Katamanso District. Generally, the metropolis stretches between latitude $5^{\circ} 37^{\prime} \mathrm{N}$ in the southern coastline and latitude $5^{\circ} 41^{\prime} \mathrm{N}$ at its northern most limits. The Accra-Tema Motorway delimits its northern boundary. The eastern and western boundaries fall within longitudes $0.0^{\prime}$ and $0.5^{\prime} \mathrm{W}$ respectively. The Greenwich Meridian (Longitude zero) passes through the Metropolis and situated only about $5^{\circ} \mathrm{N}$ from the Equator. Tema Metropolis is considered as being the city in the center of the world.

The population of male adults 18 years and above is estimated to be about 100,000 from the 2010 population distribution in the Tema Metropolis [22]. The target population for the study were male adults age 18 years and above living in the Tema Metropolis who have met are the prerequisites for the inclusion into the study. Any male resident who was not in the right frame of mind to answer the questions, has not lived in the Metropolis for at least one year and was below the age of 18 years at the time of the study was excluded from participating.

\subsection{Study Design and Sample Size}

A descriptive cross-sectional study design was used to gather the needed data between January and March, 2019. The Metropolis was stratified along the main sub-Metro divisions (Tema East, Tema West and Tema Central) and the study participants were selected proportionate to the size of each stratum. Using the list of houses obtained from the Tema Metropolitan Assembly, households in the communities were randomly selected and available adult male in each household was earmark for interview. The sample size was calculated using Cochran's formula [23].

$$
n=\frac{Z^{2} \times p q}{e^{2}}=\frac{(1.96)^{2} \times(0.18 \times 0.82)}{(0.05)^{2}} \cong 227
$$

where, $n=$ sample size,

$Z=$ the $\mathrm{z}$-score that corresponds with $95 \%$ confidence interval which is 1.96 ,

$p=$ prevalence rate of men involved in family planning (18\%) [24],

$q=$ proportion of men who are not involved in family planning,

$e=$ margin of error set at $5 \%(0.05)$.

\subsection{Data Collection and Management}

A structured questionnaire was used to source information from respondents. The questionnaire design included both close-ended and open-ended questions and captured the knowledge and perceptions of men about family planning and identifies various barriers that affect male involvement in family planning. The questionnaire was pretested in the Krowo Municipal which is a district with similar socio-demographic characteristics as the Tema Metropolis. 
The data collected were analyzed using STATA statistical software package (StataCorp.2007. Stata Statistical Software. Release 14. StataCorp LP, College Station, TX, USA). Frequencies were run for key variables and the results were presented in tables. Bivariate analyses using Pearson's Chi-square tests were performed to test the level of association between male involvement in family planning and selected socio-demographic characteristics. Multiple logistic regression was used to examine the predictors of male involvement in family planning. Odds ratios (OR) and their $95 \%$ confidence intervals were used to assess the strength of association. In all statistical analyses, a p-value of 0.05 was used to determine statistical significance.

\subsection{Study Variables}

The dependent variable in the study is composite variables comprising questions covering respondent interest and practical involvement in family planning such as "ever discussed family planning with wife, ever attended family planning clinic, ability to make time off busy schedule to attend family planning". The independent variables included: socio-economic indicators, demographic profile, cultural environment of men, male perception of family planning, awareness and knowledge of existing family planning methods, spousal communication, health systems and policies set in place.

\subsection{Ethical Consideration}

Ethical approval for the study was obtained from the Ethical Review Committee of Ensign College of Public Health and administrative permission was sought from the Tema Metro office of Ghana Health Service (GHS). Signed individual informed consent was obtained from each participant before they proceeded to answer the questionnaire. Study participants were informed of their right to opt-out of the study at any time they feel uncomfortable with the posed questions or feel physically and mentally harmed in the course of the data collection. Confidentiality of collected information was ensured.

\section{Results}

\subsection{Study Population Characteristics}

All the 227 targeted respondents opt to participate in the study resulting in a $100 \%$ response rate. The majority $(52.86 \%)$ of them were in the $33-45$ years age group. Also, the majority (87.8\%) of the respondents had a secondary or higher education whilst only $3.52 \%$ of the respondents had attained primary education. About two-thirds (63.88\%) of the respondents were married and the rest were not. A little over half (53.74\%) of the respondents were employed, $6.6 \%$ were unemployed and $40 \%$ were self-employed. With regards to participants' professed religious beliefs and practices, the Orthodox formed about a quarter of the sample (25.3\%), the Charismatic formed less than half (43.17\%) and Catholic formed twenty percent $(20.26 \%)$ of respondents (Table 1 ). 
Table 1. Demographic characteristics of the respondents.

\begin{tabular}{|c|c|c|}
\hline Factors & Frequency & Percentage (\%) \\
\hline \multicolumn{3}{|l|}{ Age group } \\
\hline $19-32$ & 85 & 37.44 \\
\hline $33-45$ & 120 & 52.86 \\
\hline $46-58$ & 22 & 9.69 \\
\hline \multicolumn{3}{|l|}{ Education } \\
\hline Tertiary & 136 & 59.91 \\
\hline SHS & 61 & 26.87 \\
\hline JHS & 22 & 9.69 \\
\hline Primary & 8 & 3.52 \\
\hline \multicolumn{3}{|l|}{ Marital Status } \\
\hline Married & 145 & 63.88 \\
\hline Not married & 82 & 36.12 \\
\hline \multicolumn{3}{|c|}{ Employment Status } \\
\hline Unemployed & 15 & 6.61 \\
\hline Employed & 122 & 53.74 \\
\hline Self-employed & 90 & 39.65 \\
\hline \multicolumn{3}{|c|}{ Religious Beliefs } \\
\hline Catholic & 46 & 20.26 \\
\hline Charismatic & 98 & 43.17 \\
\hline Orthodox & 59 & 25.99 \\
\hline Moslem & 14 & 6.17 \\
\hline Traditional & 10 & 4.41 \\
\hline
\end{tabular}

\subsection{Respondent's Perception about Family Planning}

Majority (83.26\%) of the participants, revealed their communities accept the act of men accompanying their wives or partners for family planning services, though $36.12 \%$ of them reported that their family and friends see it strange for men to attend family planning with their wives/partners. A little over two-thirds $(68.72 \%)$ of the respondents disagreed in total when asked if family planning is an issue for only women. More than half (52\%) of the respondents stated men who are involved in family planning, are not stigmatized, but $34 \%$ of them indicated that their communities consider men involved in family planning as abnormal. Concerning barriers to male involvement in family planning, less than half $(40.53 \%)$ of the respondents indicated the cost is normal. Half of the respondents (51.4\%) indicated that it takes them less than 30 mins travel to a family planning clinic. The time spent at a clinic was considered normal by most of the respondents since the majority (44.4\%) said they spend less than an hour. More than three-quarters $(78.5 \%)$ of the participants said the family planning staffs 
were friendly and beyond and health talks given at family planning clinics were very helpful as $94 \%$ of respondents attested to that, though $2 \%$ said its complete waste of time (Table 2).

Table 2. Respondent's perception on family planning.

\begin{tabular}{|c|c|c|}
\hline Factors & Frequency & Percentages (\%) \\
\hline \multicolumn{3}{|c|}{ Community Acceptability } \\
\hline Yes & 189 & 83.26 \\
\hline No & 38 & 16.74 \\
\hline \multicolumn{3}{|c|}{ Family Planning is an issue for women } \\
\hline Strongly disagree & 100 & 44.05 \\
\hline Disagree & 56 & 24.67 \\
\hline Neutral & 29 & 12.78 \\
\hline Agree & 13 & 5.73 \\
\hline Strongly agree & 29 & 12.78 \\
\hline \multicolumn{3}{|c|}{ Family and Friends reaction } \\
\hline Strangely & 82 & 36.12 \\
\hline Praise Him & 46 & 20.26 \\
\hline Indifferent & 99 & 43.61 \\
\hline \multicolumn{3}{|c|}{ Community Stigmatization } \\
\hline Yes & 109 & 48.02 \\
\hline No & 118 & 51.98 \\
\hline \multicolumn{3}{|c|}{ Pressure from relatives to have more children } \\
\hline Yes & 81 & 35.68 \\
\hline No & 146 & 64.32 \\
\hline \multicolumn{3}{|c|}{ Description given to men who patronize FP } \\
\hline Helpful & 58 & 25.55 \\
\hline Responsible & 50 & 22.03 \\
\hline Normal & 39 & 17.18 \\
\hline Abnormal & 77 & 33.92 \\
\hline Poor & 3 & 1.32 \\
\hline \multicolumn{3}{|c|}{ Cost of accessing Family planning services } \\
\hline Expensive & 55 & 24.23 \\
\hline Normal & 92 & 40.53 \\
\hline Cheap & 48 & 21.15 \\
\hline No idea & 32 & 14.1 \\
\hline \multicolumn{3}{|c|}{ Length of time at Family planning services } \\
\hline Less than 1 hour & 102 & 44.93 \\
\hline $1-2$ hours & 79 & 34.8 \\
\hline $2-3$ hours & 34 & 14.98 \\
\hline $3-5$ hours & 9 & 3.96 \\
\hline
\end{tabular}




\section{Continued}

More than 5 hours

3

Perception of the time spent for FP services

Short

Normal

Too long

The attitude of family planning staff

Very friendly

Friendly

Indifferent

Unfriendly

Rude

Perception of health talks at FP services

Very helpful

Helpful

Unhelpful

Complete waste of time

How long it takes to get to FP clinic

less than 30 mins

30 mins to 1 hour

1 - 2 hours

More than 2 hours

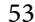

Regarding respondents' knowledge of family planning more than half (59.47\%) reported they knew sufficiently and also a lot about family planning, whilst only $3.96 \%$ admitted not knowing anything about family planning.

\subsection{Enabling Factors for Male Involvement in Family Planning}

Table 3 shows other enabling factors that encourage male involvement in family planning. About $60.8 \%$ of respondents had discussed family planning issues with their wives or partners and most respondents (78.26\%) felt normal during family planning discussion though $11.60 \%$ and $10.14 \%$ of respondents felt shy and embarrassed respectively during the discussion. Most respondents (81.94\%) had seen and read about family planning from many sources most predominantly the electronic media. The proximity of family planning center to most respondents $(66 \%)$ was close though there were no special arrangements for men said by $62 \%$ of respondents.

\subsection{Male Participation in Family Planning}

Concerning male participation in family planning, the results revealed that most $(65.6 \%)$ of the respondents have never attended any family planning clinic. 
Table 3. Factors that encourage male involvement in family planning.

\begin{tabular}{|c|c|c|}
\hline Factors & Frequency & Percentage (\%) \\
\hline \multicolumn{3}{|c|}{ Discussed FP with partner/wife } \\
\hline Yes & 138 & 60.79 \\
\hline No & 89 & 39.21 \\
\hline \multicolumn{3}{|c|}{ Respondent's feeling during FP discussion with partner/wife } \\
\hline Normal & 108 & 78.26 \\
\hline Shy & 16 & 11.60 \\
\hline Embarrassed & 14 & 10.14 \\
\hline \multicolumn{3}{|c|}{ Respondent saw/read about FP from source } \\
\hline Yes & 186 & 81.94 \\
\hline No & 41 & 18.06 \\
\hline \multicolumn{3}{|c|}{ Respondent sources of FP information } \\
\hline Internet & 37 & 19.89 \\
\hline Media & 136 & 73.12 \\
\hline Organization/Work & 13 & 6.99 \\
\hline \multicolumn{3}{|c|}{ Proximity of FP facility to respondent resident } \\
\hline Very close & 59 & 25.99 \\
\hline Close & 104 & 45.81 \\
\hline Far & 58 & 25.55 \\
\hline Very Far & 6 & 2.64 \\
\hline \multicolumn{3}{|c|}{ FP special arrangement for men } \\
\hline Yes & 87 & 38.33 \\
\hline No & 140 & 61.67 \\
\hline
\end{tabular}

Among the $34.4 \%$ who reported ever attending any such family planning clinic, $56.41 \%$ have attended just once. Most of the respondents (76.65\%) indicated family planning is important and are ready to recommend to friends to also attend (Table 4).

The common perceived challenge of family planning indicated by the respondents was the few methods and side effects. Most (15.4\%) of the respondent said the most common problems of family planning face by men who engage in family planning is lack of knowledge, followed by cultural beliefs (14.98\%), stigma (14.54\%), the least mentioned problem was unsupportive wife $(1.32 \%)$ even though $73.1 \%$ of the respondents said family planning does not have side effect.

Regarding the perceived side effects, the majority (61.7\%) of the respondents indicated impotence as the common side effect, followed by high blood pressure (20\%) and a small proportion of them (1.7\%) indicated scrotal pain as a known side effect. Respondents were asked why most males don't go for family planning. $27.75 \%$ of them attributed it to shyness and stigma, $27.31 \%$ thought it is for 
Table 4. Level of male participation in family planning.

\begin{tabular}{|c|c|c|}
\hline Factors & Frequency & Percentage (\%) \\
\hline \multicolumn{3}{|l|}{ Ever attended FP clinic } \\
\hline Yes & 78 & 34.36 \\
\hline No & 149 & 65.64 \\
\hline \multicolumn{3}{|l|}{ Number of times attended FP } \\
\hline Once & 44 & 56.41 \\
\hline Twice & 20 & 25.64 \\
\hline Thrice & 5 & 6.41 \\
\hline Four or more & 9 & 11.54 \\
\hline \multicolumn{3}{|l|}{ Importance of FP to Respondents } \\
\hline Not important & 26 & 11.45 \\
\hline Important & 84 & 37 \\
\hline Very important & 77 & 33.92 \\
\hline Extremely important & 40 & 17.62 \\
\hline \multicolumn{3}{|l|}{ Recommend FP to friend/relative } \\
\hline Yes & 174 & 76.65 \\
\hline No & 53 & 23.35 \\
\hline \multicolumn{3}{|l|}{ Any challenges accessing FP services } \\
\hline Yes & 25 & 32.05 \\
\hline No & 53 & 67.95 \\
\hline \multicolumn{3}{|l|}{ Main challenges to FP } \\
\hline Lack of male FP providers & 26 & 11.45 \\
\hline Stigmatization & 23 & 14.54 \\
\hline Masculinity power & 26 & 11.45 \\
\hline Wives with negative community perception & 11 & 4.85 \\
\hline Unsupportive & 3 & 1.32 \\
\hline Peer pressure & 8 & 3.52 \\
\hline Fewer contraceptive methods & 22 & 9.69 \\
\hline Lack of knowledge about FP & 35 & 15.42 \\
\hline Shyness & 29 & 12.78 \\
\hline Cultural beliefs & 34 & 14.98 \\
\hline \multicolumn{3}{|l|}{ Know of Side effects of FP for men } \\
\hline Yes & 61 & 26.87 \\
\hline No & 166 & 73.13 \\
\hline
\end{tabular}

women, $19.38 \%$ of them indicated masculine power, and $12.33 \%$ of them indicate lack of education on family planning, only a small percentage $(5.29 \%)$ of respondent said they had no time, though $7.93 \%$ of them said it due to cultural reasons. 


\subsection{Bivariate Analysis between Demographic Characteristics and Male Involvement in Family Planning}

Table 5 represents bivariate analysis on factors associated with male involvement in family planning in Tema Metropolis. There was no observed statistical significant association between age groups and male involvement ( $p=0.087)$. Similar observation was made between the educational level of respondents and their involvement in family planning $(\mathrm{p}=0.198)$. However, the analysis revealed there were very significant associations between involvement in family planning and the participants' marital status, employment status and their level of knowledge on family planning services at $(\mathrm{p}=0.004),(\mathrm{p}=0.002)$ and $(\mathrm{p}=0.001)$ respectively.

Table 5. Bivariate analysis of male involvement in FP and selected demographic characteristics.

\begin{tabular}{|c|c|c|c|}
\hline \multirow{2}{*}{ Factors } & \multicolumn{3}{|c|}{ Male involvement in Family planning } \\
\hline & Yes & No & p-value \\
\hline \multicolumn{4}{|l|}{ Age group } \\
\hline $19-32$ & $32(41.03)$ & $53(35.57)$ & 0.087 \\
\hline $33-45$ & $43(55.13)$ & $77(51.68)$ & \\
\hline $46-58$ & $3(3.85)$ & $19(12.75)$ & \\
\hline \multicolumn{4}{|l|}{ Education } \\
\hline Tertiary & $50(64.10)$ & $86(57.72)$ & 0.198 \\
\hline SHS & $23(29.49)$ & $38(25.50)$ & \\
\hline JHS & $4(5.13)$ & $18(12.08)$ & \\
\hline Primary & $1(1.28)$ & $7(4.69)$ & \\
\hline \multicolumn{4}{|l|}{ Marital Status } \\
\hline Married & $60(76.92)$ & $85(57.05)$ & 0.004 \\
\hline Not Married & $18(23.08)$ & $64(42.95)$ & \\
\hline \multicolumn{4}{|l|}{ Employment Status } \\
\hline Employed & $53(67.95)$ & $69(46.31)$ & 0.002 \\
\hline Unemployed & $6(7.69)$ & $9(6.04)$ & \\
\hline Self Employed & $19(24.36)$ & $71(47.65)$ & \\
\hline \multicolumn{4}{|c|}{ Knowledge about FP } \\
\hline Knows nothing & $1(1.28)$ & $8(5.37)$ & 0.001 \\
\hline Knows very little & $16(20.51)$ & $67(44.97)$ & \\
\hline Knows sufficiently & $46(58.97)$ & $61(40.94)$ & \\
\hline Knows a lot & $15(19.23)$ & $13(8.72)$ & \\
\hline
\end{tabular}

\subsection{Multivariate Logistic Regression Analysis of Factors Associated with Male Involvement in Family Planning}

Table 6 presents the multivariate logistic regression analysis of factors associated 
with socio-demographic characteristics on male involvement in family planning. Males within age-group (33 - 45) were 0.2 times less likely to be involved in family planning compared to those within the age-group (19-32) (AOR $=0.83,95 \%$ CI: 0.43 - 1.59). Also, males within the age (46-58) were 0.8 times less likely to be involved in family planning compared the young age group $(19-32)(\mathrm{AOR}=$ $0.17,95 \%$ CI: $0.04-0.70)$ controlling for all other covariates. In relation to education, males who are with SHS and Tertiary levels of education are 3.8 times and 1.9 times respectively more likely to be involved in family planning compared to those with primary education adjusting for all other variables in the model. Males who were not married were 0.6 times less likely to be involved in family planning than men who are married (AOR $=0.39,95 \%$ CI $0.20-0.78$ ). Those who are self-employed were significantly involved in family planning, though 0.7 times less like to be involved compared to those unemployed $(\mathrm{AOR}=$ 0.26, 95\% CI: 0.07 - 0.97).

Males who are employed were also 0.1 times less likely to be involved compared to those unemployed. In relation to respondent's religious beliefs, Catholics were 0.1 times less likely to be involved in family planning compared to the traditionalist ( $\mathrm{AOR}=0.89,95 \% \mathrm{CI}: 0.15-5.40$ ) as well as the Moslem who were 0.2 times less likely unlike the Orthodox or Charismatic respondents who were 2 times more likely to be involved in family planning. Respondents who knew a lot and sufficiently were 9 times and 5 times more likely respectively to be involved in family planning ( $\mathrm{AOR}=8.79,95 \% \mathrm{CI}: 0.81-95.89)(\mathrm{AOR}=4.93,95 \% \mathrm{CI}$ : 0.51 - 47.25). In summary, after adjustment, only three factors stood out significant. These included men who were within age groups (46 - 58), men who were not married and those who were self-employed. The model was good with a p-value of 0.75 from the Pearson's goodness-of-fit test of the model.

Table 6. Multivariate logistic regression analysis of factors associated with male involvement in family planning.

\begin{tabular}{lllll}
\hline FACTORS & p-value & $\begin{array}{l}\text { UNADJUSTED OR } \\
(95 \% \mathrm{CI})\end{array}$ & p-value & $\begin{array}{l}\text { ADJUSTED OR } \\
(95 \% \mathrm{CI})\end{array}$ \\
\hline Age-groups & Reference & 1 & & 1 \\
$19-32$ & 0.791 & $0.92(0.52-1.65)$ & 0.571 & $0.83(0.43-1.59)$ \\
$33-45$ & 0.042 & $0.26(0.07-0.95)$ & 0.014 & $0.17(0.04-0.70)$ \\
$46-58$ & Reference & 1 & & 1 \\
Educational Level & 0.714 & $1.56(0.15-16.46)$ & 0.602 & $2.02(0.14-28.58)$ \\
Primary & 0.190 & $4.24(0.49-36.67)$ & 0.281 & $3.79(0.34-42.88)$ \\
JHS & 0.195 & $4.07(0.49-34.04)$ & 0.620 & $1.85(0.16-21.00)$ \\
SHS & & & & \\
Tertiary & Reference & 1 & & 1 \\
Marital Status & & & & \\
Married & & & & \\
\hline
\end{tabular}




\section{Continued}

\begin{tabular}{|c|c|c|c|c|}
\hline Not married & 0.004 & $0.40(0.21-0.74)$ & 0.008 & $0.39(0.20-0.78)$ \\
\hline \multicolumn{5}{|l|}{ Employment Status } \\
\hline Unemployed & Reference & 1 & & 1 \\
\hline Employed & 0.800 & $1.15(0.39-3.44)$ & 0.803 & $0.86(0.25-2.91)$ \\
\hline Self Employed & 0.120 & $0.40(0.13-1.27)$ & 0.045 & $0.26(0.07-0.97)$ \\
\hline \multicolumn{5}{|l|}{ Religion } \\
\hline Traditional & Reference & 1 & & 1 \\
\hline Catholic & 0.978 & $1.02(0.23-4.53)$ & 0.899 & $0.89(0.15-5.40)$ \\
\hline Charismatic & 0.719 & $1.29(0.32-5.33)$ & 0.613 & $1.57(0.27-9.02)$ \\
\hline Orthodox & 0.658 & $1.39(0.32-5.93)$ & 0.536 & $1.75(0.30-10.30)$ \\
\hline Moslem & 0.939 & $0.93(0.16-5.54)$ & 0.836 & $0.80(0.10-6.45)$ \\
\hline \multicolumn{5}{|c|}{ Knowledge about FP } \\
\hline Knows nothing & Reference & 1 & & 1 \\
\hline Knows very little & 0.555 & $1.91(0.22-16.39)$ & 0.604 & $1.83(0.19-17.99)$ \\
\hline Knows sufficiently & 0.096 & $6.03(0.73-49.95)$ & 0.167 & $4.93(0.51-47.25)$ \\
\hline Knows a lot & 0.048 & $9.23(1.02-83.94)$ & 0.075 & $8.79(0.81-95.89)$ \\
\hline
\end{tabular}

\section{Discussion}

The study found most $(52.86 \%)$ of the respondents to be middle-aged adults between 33 and 45 years with the entire respondents between age 19 - 58 which had similar findings to a study in Lome, Togo [25]. Also, most of the respondents $(86.7 \%)$ had Secondary school or higher level of education which contradicts study findings in Kibaha district in Tanzania where the highest level of formal education attained by most respondents (65.5\%) was primary education [26]. Majority of the respondents were married as well as a little over half of them were employed. In addition, Charismatic participants were the majority followed by Orthodox participants then the Catholics.

From the analyzed data it was observed that majority of respondents in the studied area (83.26\%) accept the act of male spouses accompanying their partners for family planning services. This finding, however, was contrary to the findings from a study in the Kassena-Nankana District in the Northern part of Ghana where women opting to practice family planning must do so at considerable risk of social ostracism or familial conflict [27] and not even thinking of male partners accompanying them to family planning clinic. The results of the study revealed that most men strongly disagreed that family planning is an issue for women which was contrary to findings in Malawi, where family planning is seen as a women's domain and because of this, male involvement in Family Planning remains lower than wanted [28].

On assessing the knowledge level of the study participants on family planning, it was revealed that more than half of the men had sufficient knowledge about 
family planning. The finding in this study was similar to other related studies, such as a survey conducted by GDHS (2003) [29], where $99 \%$ of all men know at least one method of contraception. On the contrary, a study conducted in Mpigi District in Uganda revealed that men have limited knowledge about family planning and that family planning service does not adequately meet the needs of men [30].

The study showed that about sixty percent $(60.8 \%)$ of respondents had discussed family planning with wives or partners which was similar to a study by Thapa et al. (2013) which showed intra-spousal communication to be positively associated with husbands' presence at a health facility delivery thereby increasing male involvement in family planning [31]. A question to tease out respondents' perception of the cost of family planning services and the time spent at family planning services showed they found each of them to be in the expected ranges. Majority indicated time to arrive at family planning centres was less than 30 minutes which was similar to study done by Eni in 2005, where the majority of the clients had to travel for the services at less cost [32].

Majority of respondents said family planning staffs in the facilities they visit were friendly and health talks given at family planning clinic area very helpful even though 62 percent (62\%) of respondents mentioned there is no special arrangement for men at family planning services as reported Tekou et al., 2018 that women have greater motivation than men to use family planning services, and they usually interact more with health care services in general than men [25]. Most respondents (81.94\%) get their information about family planning from the media which was similar to research done in rural Uganda where 73\% of men reported obtaining information via radio [33].

Concerning barriers to male participation in family planning the results reveal that most of the respondents (65.6\%) had never attended family planning which is similar to a finding from a study conducted in Chorkor, an inner city in Ghana, where only (6.6\%) have ever accompanied their wives/partners to the Family Planning clinic [34].

This study also revealed that among those who had ever attended a family planning clinic, the majority (54.61\%) had attended once, which has similar findings to that in communities in Afar, Ethiopia where husbands' involvement in family planning was about $42.2 \%$ [35]. However, most of the respondents indicated family planning is important and are ready to recommend to friends. Fifteen percent (15.4\%) of the respondent said the most common problem of family planning face by men who engage in family planning is lack of knowledge which was similar to study by Mullany in 2006 which found that lack of knowledge about maternal health among Nepalese husbands impedes positive involvement in maternal health care [18]. This was followed by cultural beliefs (14.98\%) then stigma (14.54\%) as also noted by Thapa et al. (2013) suggest that fear of social stigma and feelings of shame for supporting their wife, elaborating on the traditional cultural norms that attach a negative value to husbands who 
play a supportive role during their wife's maternity period affects male involvement in family planning [31]. Regarding the side effects, the majority (61.7\%) of the respondents indicated impotence as the common side effects followed by high blood pressure (20\%) and a small proportion of them (1.7\%) indicated scrotal pain as a known side effect. Most men boast of their sexual performance and if family planning method will render them unable to perform well then it will deter them from involving in family planning as also stated in another study by Kassa et al. (2014) that perceived fear of side effects were the part of factors causing low patronage of family planning by men [36].

Regarding respondents' perceptions, the reasons why men generally do not attend family planning clinic. About $28 \%$ said it was due to shyness and $27 \%$ mentioned it being more women-oriented. This result is similar to a demographic health survey conducted in Ilorin-Nigeria, where family planning clinics were oriented towards women, therefore, men felt uncomfortable and shy in these clinics [20].

The factors identified to be associated with male involvement in family planning clinics in this study include the reported marital status, employment status and knowledge about family planning. Male who were married were more likely to be involved in family planning that those not married which was contrary to the findings in a study by Apanga et al. (2015) in the Talensi district in Ghana where marital status was not associated with male involvement in family planning [37]. Also, males who were employed have a much higher likelihood to be involved in family planning clinics compared to their counterparts that reported being unemployed at the time of participating in the study. Men who knew sufficiently and a lot about family planning were more likely to be involved in family planning compared to those who knew nothing which was similar to study by Apanga et al. (2015) which stated that educational level was positively associated with usage of family planning services [37]. These factors were so because married and employed men tend to be more responsible and want to plan their family sizes. The same is true of those who knew much about family planning. Those who knew much about family planning are aware of the various methods and their benefits.

In the unadjusted multivariate analyses, age groups, marital status and those who knew a lot about family planning stood out significant to influence male involvement in family planning. The predictive factors were age group (46 - 58) years, unmarried men and those who knew a lot about family planning which was similar to the results from the GDHS, 2008 study, where men who knew a lot will use a form of contraception and were involved in family planning compared to illiterate men [38].

After adjusting for other predictor variables in the model, only three factors such as age group (46 - 58), unmarried men and those who were self-employed significantly influence male involvement in family planning. It could be deduced that men aged (46 - 58) years are probably finished childbearing, getting to their 
retirement and would want to get involved in family planning to avoid unwanted pregnancies. This will prevent the high dependency burden of childbearing and also help them plan for their retirement. This was contrary to a study in Catalonia [39] where older age was not a factor influencing male involvement in family planning but in another study done in Malaysia, Kuala Lumpur city in a primary care clinic men age 45 years and beyond was associated with involvement in family planning [40]. Unmarried men will use a form of male contraception as well as influence their partners to get involved in family planning because they are not married and would prevent unwanted pregnancy which would help in the uptake of family planning, unlike the married men who will not bother if their wives get pregnant or not and will not use any form of male contraception that has contributed to the high unmet need of family planning among married women of about $30 \%$ according to the GDHS, (2014). Men who were self-employed significantly influence male involvement in family planning which was contrary to study in Debremarkos town in Ethiopia [37] where males who were unemployed and discussed family planning with spouse influence their involvement in family planning.

\section{Conclusions}

Family planning is not an issue that concerns just women in their reproductive ages but the whole family unit given they are married and to some extent the larger community. Communities are gradually accepting the act of men accompanying their wives or partners for family planning services though few family and friends see it strange for men to do so. Concerning the constraints to male involvement in family planning which this sought to explore, it has been established that cost and time spent at the family planning clinic were normal and staffs at the family planning unit were friendly.

It was further established from the gathered data that most men have never attended any family planning clinic. However, among those who did, most of them have attended it once, even though the majority of respondents said family planning is important and would recommend it to friends and relatives. The main challenges preventing men from involving themselves and also accompanying their spouses to the family planning clinics include: lack of knowledge on the available services provided at a facility, cultural beliefs, and societal ridicule and stigmatization for patronizing family planning. Other perceived challenges identified from the study were fewer methods of services to choose from and side effects associated with family planning. There was a significant association between factors such as marital status, employment status and knowledge about family planning in relation to male involvement in family planning but after adjusting for other covariates the oldest age group, unmarried men and being self-employed were the only factors that influence male involvement in family planning. Future research work should explore the use of a qualitative approach to help unearth in detail the factors hovering around the lackadaisical attitude of 
male involvement in this all-important part of life.

\section{Authors' Contributions}

This work was carried out in collaboration between all authors. KM and SM participated in conceiving the study and in the development of data collection tools. KM carried out data collection. SM and KM participated in the data analysis and drafting of the manuscript. All authors read and approved the final manuscript.

\section{Conflicts of Interest}

All authors declare no conflict of interest.

\section{References}

[1] Cates, W. (2010) Family Planning: The Essential Link to Achieving All Eight Millennium Development Goals. Contraception, 81, 460-461.

https://doi.org/10.1016/j.contraception.2010.01.002

[2] Reynolds, H.W., Janowitz, B., Wilcher, R. and Cates, W. (2008) Contraception to Prevent HIV-Positive Births: Current Contribution and Potential Cost Savings in PEPFAR Countries. Sexually Transmitted Infections, 84, 49-53. https://doi.org/10.1136/sti.2008.030049

[3] Cleland, J., Conde-Agudelo, A., Peterson, H., Ross, J. and Tsui, A. (2012) Contraception and Health. The Lancet, 380, 149-156. https://doi.org/10.1016/S0140-6736(12)60609-6

[4] Rustein, S.O. (2005) Effects of Preceding Birth Intervals on Neonatal, Infant and Under-Five Years Mortality and Nutritional Status in Developing Countries: Evidence from the Demographic and Health Surveys. International Journal of Gynecology \& Obstetrics, 89, S7-S24. https://doi.org/10.1016/j.ijgo.2004.11.012

[5] Sedgh, G., Singh, S., Shah, I.H., Åhman, E., Henshaw, S.K. and Bankole, B. (2012) Induced Abortion: Incidence and Trends Worldwide from 1995 to 2008. The Lancet, 379, 625-632. https://doi.org/10.1016/S0140-6736(11)61786-8

[6] Singh, S., Darroch, J.E., Ashford, L.S. and Vlassoff, M. (2009) Adding It Up: The Costs and Benefits of Investing in Family Planning and Maternal and Newborn Health. Guttmacher Institute and United Nations Population Fund (UNFPA), New York. http://www.guttmacher.org/pubs/AddingItUp2009.pdf

[7] WHO Country Statistics (2007). http://who.int/nha/country/gha/Ghana_NHA_report

[8] Obionu, C.N. (1998) Family Planning Knowledge Attitude and Practice among Males in a Nigerian Urban Population. East Africa Medical Journal, 75, 131-134. https://www.ncbi.nlm.nih.gov/pubmed/9640807

[9] Bassett, S., Tsui, A.O., Plotkin, M. and Bloom, S.S. (2000) What Husbands in Northern India Know about Reproductive Health: Correlates of Knowledge about Pregnancy and Maternal and Sexual Health. Journal of Biosocial Science, 32, 237-251. https://doi.org/10.1017/S0021932000002376

[10] Ijadunola, M.Y., Abiona, T.C., Ijadunola, K.T., Afolabi, O.T., Esimai, O.A. and OlaOlorun, F.M. (2010) Male Involvement in Family Planning Decision Making in Ile-Ife, Osun State, Nigeria. African Journal of Reproductive Health, 14, 43-50. https://www.ncbi.nlm.nih.gov/pubmed/21812197 
[11] Ashraf, L. and Stan, B. (1997) Husband-Wife Communication about Family Planning and Contraceptive Use in Kenya. International Family Planning Perspectives, 23, 15-20 + 33. https://www.jstor.org/stable/2950781?seq=1 https://doi.org/10.2307/2950781

[12] Alex, E. (1993) The Influence of Spouses over Each Other's Contraceptive Attitudes in Ghana. Studies in Family Planning, 24, 163-174.

https://www.jstor.org/stable/293923 https://doi.org/10.2307/2939231

[13] Adanu, R.M.K., Seffah, J.D., Hill, A.G., Darko, R., Duda, R.B. and Anarfi, J.K. (2009) Contraceptive Use by Women in Accra, Ghana: Results from the 2003 Accra Women's Health Survey. African Journal of Reproductive Health, 13, 123-133. https://www.ncbi.nlm.nih.gov/pubmed/20687270

[14] Ghana Statistical Service (2012) Ghana Multiple Indicator Cluster Survey with an Enhanced Malaria Module and Biomarker. Final Report, Accra. https://www.dhsprogram.com/pubs/pdf/FR262/FR262.pdf

[15] Ghana Statistical Service (2014) Ghana Demographic and Health Survey Report. Accra. https://dhsprogram.com/pubs/pdf/SR224/SR224.pdf

[16] Dewi, V. (2009) Factors That Influence Male Participation in Family Planning and Reproductive Health in Indonesia. Master Thesis, the Flinders University of South Australia, Adelaide. (Unpublished)

[17] Arundhati, C. (2011) Male Involvement in Family Planning and Reproductive Health in Rural Central India. Academic Dissertation University of Tampere, School of Health Sciences International Postgraduate Programme in Epidemiology Finland, Tampere, 1.

https://trepo.tuni.fi/bitstream/handle/10024/66834/978-951-44-8658-6.pdf;jsessioni d

[18] Mullany, B.C. (2006) Barriers to and Attitudes towards Promoting Husbands' Involvement in Maternal Health in Katmandu, Nepal. Social Science \& Medicine, 62, 2798-2809. https://doi.org/10.1016/j.socscimed.2005.11.013

[19] Adongo, P.B., Phillips, J.F. and Baynes, C.D. (2006) Addressing Men's Concerns about Reproductive Health Services in a Rural Sahelian Setting of Northern Ghana: The "Zurugelu Approach". African Journal Reproductive Health, 10, 1-31. https://paa2012.princeton.edu/papers/122357

[20] Olawepo, R.A. and Okedare, E.A. (2006) Men's Attitudes towards Family Planning in a Traditional Urban Centre: An Example from Ilorin, Nigeria. Journal of Social Sciences, 13, 83-90. https://doi.org/10.1080/09718923.2006.11892535

[21] Khalifa, M.A. (1988) Attitude of Urban Sudanese Men towards Family Planning. Studies in Family Planning, 19, 236-243.

https://www.ncbi.nlm.nih.gov/pubmed/3176096

https://doi.org/10.2307/1966555

[22] Tema Metro Health Directorate (2010). http://www2.statsghana.gov.gh/docfiles/2010_District_Report/Greater\%20Accra/Te ma\%20Metro.pdf

[23] Cochran, W.G. (1977) Sampling Techniques. 3rd Edition, Wiley, New York, 428 p. https://archive.org/details/Cochran1977SamplingTechniques_201703/page/n115

[24] Ndenzako, F.N. (2001) Male Contraceptive Prevalence and Factors Associated with Contraceptive Use among Men in Ngara, Tanzania. https://core.ac.uk/download/pdf/30859069.pdf 
[25] Koffi, T.B., Weidert, K., OuroBitasse, E., Mensah, M., Emina, J., Mensah, S., Prata, N., et al. (2018) Engaging Men in Family Planning: Perspectives from Married Men in Lomé, Togo. Global Health, Science, and Practice, 6, 317-329. https://doi.org/10.9745/GHSP-D-17-00471

[26] Msovela, J., Tengia-Kessy, A. and Mubyazi, G.M. (2016) Access to Family Planning Information and Contraception Methods Use among Tanzanian Men: A Cross-Sectional Study in Kibaha District. Journal of Epidemiology and Preventive Medicine, 2, 119. https://doi.org/10.19104/jepm.2016.119

https://www.elynsgroup.com/journal/article/access-to-family-planning-information -and-contraception-methods-use-among-tanzanian-men-a-cross-sectional-study-in -kibaha-district

[27] Adongo, P.B., Phillips, I.J.F., Kajihara, B., Fayorsey, C., Debpuur, C. and Binka, F.N. (1997) Cultural Factors Constraining the Introduction of Family Planning among Kassena-Nankana of Northern Ghana. Social Science \& Medicine, 45, 1789-1804. https://doi.org/10.1016/S0277-9536(97)00110-X

[28] Dral, A.A., Tolani, M.R., Smet, E. and Luijn, A.V. (2018) Factors Influencing Male Involvement in Family Planning in Ntchisi District, Malawi-A Qualitative Study. African Journal of Reproductive Health, 22, 35-43. https://doi.org/10.29063/ajrh2018/v22i4.4

[29] Ghana Statistical Service (2003) Ghana Demographic and Health Survey Report. Accra. https://www.dhsprogram.com/pubs/pdf/FR152/FR152.pdf

[30] Kaida, A., Kipp, W., Hessel, P. and Konde-Lule, J. (2005) Men's Perception about Family Planning. Journal of Biosocial Science, 37, 269-286. https://doi.org/10.1017/S0021932004007035

[31] Thapa, D.K. and Niehof, A. (2013) Women's Autonomy and Husbands' Involvement in Maternal Healthcare in Nepal. Social Science \& Medicine, 93, 1-10. https://doi.org/10.1016/j.socscimed.2013.06.003

[32] Eni, G. (2005) Male Perception in Family Planning, a Case Study in Khaochakan District, Sakaeo Province, Thailand. http://mulinet11.li.mahidol.ac.th/thesis/2547/cd363/4637957.pdf

[33] Dougherty, A., Kayongo, A., Deans, S., Mundaka, J., Nassali, F., Sewanyana, J. and Kalyesubula, R. (2018) Knowledge and Use of Family Planning among Men in Rural Uganda. BMC Public Health, 18, 1294. https://doi.org/10.1186/s12889-018-6173-3

[34] Atuahene, M.D., Arde-Acquah, S., Atuahene, N.F., Adjuik, M. and Ganle, J.K. (2017) Inclusion of Men in Maternal and Safe Motherhood Services in Inner-City Communities in Ghana: Evidence from a Descriptive Cross-Sectional Survey. BMC Pregnancy and Childbirth, 17, 419. https://doi.org/10.1186/s12884-017-1590-3

[35] Chekole, M.K., Kahsay, Z.H., Medhanyie, A.A., Gebreslassie, M.A. and Bezabh, A.M. (2019) Husbands' Involvement in Family Planning Use and Its Associated Factors in Pastoralist Communities of Afar, Ethiopia. Reproductive Health, 16, 33. https://doi.org/10.1186/s12978-019-0697-6

[36] Kassa, M., Abajobir, A.A. and Gedefaw, M. (2014) Level of Male Involvement and Associated Factors in Family Planning Services Utilization among Married Men in Debremarkos Town, Northwest Ethiopia. BMC International Health and Human Rights, 14, 33. https://doi.org/10.1186/s12914-014-0033-8

[37] Apanga, P.A. and Adam, M.A. (2015) Factors Influencing the Uptake of Family Planning Services in the Talensi District, Ghana. Pan African Medical Journal, 20, 10. https://doi.org/10.11604/pamj.2015.20.10.5301

[38] Ghana Statistical Service (2008) Ghana Demographic and Health Survey Report. 
Accra. https://dhsprogram.com/pubs/pdf/GF14/GF14.pdf

[39] Saurina, C., Vall-Llosera, L., Saez, M. and GESIC Collaborative Group (2012) Factors Determining Family Planning in Catalonia. Sources of Inequity. International Journal for Equity in Health, 11, 35. https://doi.org/10.1186/1475-9276-11-35

[40] Ling, J. and Tong, S.F. (2017) The Roles of Men in Family Planning-A Study of Married Men at the UKM Primary Care Clinic. Malaysian Family Physician: The Official Journal of the Academy of Family Physicians of Malaysia, 12, 2-13.

https://www.ncbi.nlm.nih.gov/pmc/articles/PMC5420317/pdf/MFP-12-02.pdf 